\title{
IMPACT OF CLIMATE CHANGE ON SOLAR IRRADIATION AND VARIABILITY OVER THE IBERIAN PENINSULA USING AN ENSEMBLE OF REGIONAL CLIMATE MODELS
}

\author{
V. Gil (1), M. A. Gaertner (2), C. Gutierrez (1) y T. Losada (3) \\ (1) Instituto de Ciencias Ambientales (ICAM). Universidad de Castilla-La Mancha. \\ (2) Facultad de Ciencias del Medio Ambiente. Universidad de Castilla-La Mancha. \\ (3) Facultad de Ciencias Físicas. Universidad Complutense de Madrid.
}

\begin{abstract}
As solar energy will be an increasingly important renewable energy source in the future years, the study of how climate change affects both temporal and spatial variability is very important. In this paper, we study future changes of the solar radiation resource in the Iberian Peninsula (IP) through a set of simulations from ESCENA project until mid-century. The evaluation of the simulations against observations indicates contrasting biases for the different regional climate models (RCMs) in terms of solar irradiation amount and its interannual variability. We propose a diagnostic for the quality of solar energy resource, in which the gridpoints are classified in four categories depending on the combination of solar irradiation amount and variability. The observed large percentage of points in the optimal category (high irradiation/low variability) in the IP is captured by the RCMs in general terms.

The analysis of scenarios indicates a future increase in solar irradiation, although not all scenarios agree in the geographical distribution of this increase. In most projections, a shift is projected from the category with optimal resource quality towards the category with high irradiation/high variability, pointing to a certain quality loss in the solar resource. This result is not general, as a few scenarios show an opposite result. The exceptions are not linked to a particular GCM or emissions scenario. Finally, results from a first approximation to the issue of the ability of solar energy to cover power demand peaks in summer show important differences between regions of the IP. The spatially-averaged correlation of solar irradiation and summer surface temperatures for the whole IP is rather high, which is a positive result as
\end{abstract}


the strong interconnections of the power grid within the IP could allow a distribution of solar power surpluses in certain regions for such high-temperature episodes.

Keywords: Solar resource; Solar variability; Iberian Peninsula; Climate change

\section{Introduction}

Iberian Peninsula has an abundant solar energy resource which remains largely unused. In comparison to wind power, installed solar power capacity is relatively small, though it has increased rapidly over the past few years. Together with the amount of solar radiation, the interannual and seasonal variability of the solar energy will significantly influence the production of future solar power plants, so that their study is very important to decide which are the best locations. Particularly, a low interannual variability will enable a stable and reliable solar energy supply. The southwestern part of IP stands out because of a low interannual variability combined with a high number of sunshine hours (Gil et al., 2015). Another point to consider in the analysis of the impact of climate change on the production of solar energy is the vulnerability to extreme weather events that can damage the installations of solar plants (Patt et al., 2013) or reduce the electricity generation capacity due to the incidence of extreme heat and drought events (Bartos et al., 2015). Electricity demand can increase strongly during strong heat waves, and solar power can contribute to cover such demand increases, if solar radiation also increases during such episodes.

Several research projects have been developed to calculate the implications of climate change in the medium and long term. The main variables studied have been temperature, precipitation and wind, while less attention has been devoted to possible changes in solar radiation. Thus, one of the motivations for this article is to study the change in solar energy caused by climate change as a principal objective. The patterns in precipitation variation are clearly related to solar insolation via cloud cover. Under cloudless skies, aerosol optical depth becomes the driving factor (Gueymard, 2012). 
Different researchers have studied the impacts of climate change on renewable energy resources at different spatial scales. Wild et al. (2015) and Crook et al. (2011) have made a global study and both obtain very similar conclusions, detecting an increase of solar energy in Europe and an almost generalized decrease in the rest of the world. Other studies focus on Europe, such as Gaetani et al. (2014), Tobin et al. (2015) or Jerez et al. (2015). The first indicates that the W of Europe and $\mathrm{E}$ of Mediterranean are the areas of greatest increase in solar energy, while Jerez et al. (2015) concludes that there will be a decline in the north of the European continent and slight increses in southern areas. Moreover, Tobin et al. (2015) studies the effect of climate change on wind and indicates a decrease in the Mediterranean and an increase in the NE of Europe. Gómez et al. (2016) also finds a future decrease of wind energy resources in the Iberian Peninsula, but with important variations among subregions. Finally, some articles have studied the potential impacts from a more local perspective. This is the case of Panagea et al. (2014) that detects an increased insolation on Greece by 2100. Pašičko et al. (2012) studies the effects of climate change in Croatia, on the three most common renewable energies, solar, wind and hydropower. Gunderson et al. (2015) focuses on the Black Sea where he finds significant variations in solar energy caused by climate change. Burnett et al. (2014) investigates the UK solar irradiation resource for the present and future climate, obtaining a general insolation increase with the exception of NW Scotland.

In terms of study periods to explore the consequences of climate change, generally, there are more analysis of the long-term (end of the century)(Dosio, 2016; Rowell, 2005; Räisänen et al., 2004) and only a few studies analyze the effects in the medium term (mid-century)(Gutowski et al., 2007). To locate the best places for future solar power plants, it will be more interesting to study the medium term, because it will be at these moment when solar plants that are projected today will be operating. This is another gap that we try to clarify with this study.

Another motivation for this article is to analyze the reliability of the solar resource for energy production over the Iberian Peninsula, through the examination of interannual and seasonal variability. The best resource areas should combine a high amount of solar resource with low interannual variability, so that the yearly produced energy does not vary much. These aspects will be studied under climate change 
conditions. To this effect, we will use simulations of ESCENA project because they focus on our study domain, in contrast to other scenarios from European projects in which the simulation boundaries are too close to the Iberian Peninsula.

Global climate models (GCMs) have insufficient spatial resolution to describe the climate at the regional level, particularly for regions with complex terrain like IP. Regionalization techniques, like the dynamical downscaling, are needed to represent smaller scales. The dynamical downscaling consists in applying regional climate models (RCMs) driven by boundary conditions which are taken from projections of a global model. The existence of different formulations of RCMs introduces new uncertainties in future climate projections. The way to evaluate this uncertainty is using a multi-model ensemble of simulations. This is based on the independence of errors for each model, even if some models have important common parts (Knutti et al., 2010). A number of EU-funded projects (PRUDENCE, Christensen and Christensen, 2007; ENSEMBLES,Van der Linden and Mitchell, 2009) have explored the use of an ensemble of regional models for estimating climate change uncertainties at a local scale in Europe. As IP lies very near to a lateral border in these European projects, we will use simulations from the project ESCENA . (http://meteo.unican.es/en/projects/escena; Jiménez-Guerrero et al., 2013; Domínguez et al., 2013). In this project, AR4 climate change scenarios have been dynamically downscaled by means of 4 different regional climate models (PROMES, WRF, MM5 and REMO), using a high resolution of $25 \mathrm{Km}$ on a domain that extends further west than that of other European projects, covering Peninsular Spain and the Balearic and Canary Islands.

This paper is organised as follows. In section 2, we describe the solar radiation measurements, the reanalysis and the different models used in this study, as well as the analysis methods applied in this article. In section 3, we show validation results for the RCMs models of ESCENA project and their behaviour under climate change scenarios. Section 4 presents the main conclusions of this study.

\section{Data and methods}


The satellite database Satellite Application Facility on Climate Monitoring (CM SAF , http://www.cmsaf.eu.) has been used as the reference for validating the simulation. The simulation results have been interpolated onto the satellite data grid in order to allow comparisons between data.

The CM-SAF is a joint venture of the Royal Netherlands Meteorological Institute, the Swedish Meteorological and Hydrological Institute, the Royal Meteorological Institute of Belgium, the Finnish Meteorological Institute, the Deutscher Wetterdienst, Meteoswiss, the UK MetOffice, with the collaboration of the European Organization for the Exploitation of Meteorological Satellites (EUMETSAT). The CM SAF provides two categories of data: operational products and climate data. Climate data are long-term data series appropriate to assess interannual variability and so we selected them for this study, in particular, the shortwave incoming solar radiation product (SIS) with a spatial resolution of $0.2^{\circ} \times 0.2^{\circ}$ as daily averages. SIS collates shortwave radiation reaching a horizontal unit earth surface obtained by processing information from geostationary satellites (SEVIRI sensor on board of the METEOSAT Second Generation). The data are available for 1983-2013 period.

Models

The ESCENA project generated climate change scenarios based on an ensemble of 4 Regional Climate Models (RCMs): PROMES, WRF (two versions with different physical parameterizations), MM5 and REMO. A brief description of each model configuration is provided in Table 1, and further information can be found in Jiménez-Guerrero et al. (2013) and Domínguez et al. (2013).

The simulations cover a large part of Europe, but we have selected a common area centred in the Iberian Peninsula (IP) which is defined from $12^{\circ} \mathrm{W}$ to $7^{\circ} \mathrm{E}$ and from $35^{\circ} \mathrm{N}$ to $45^{\circ} \mathrm{N}$.

All the simulations in the validation period (1989-2008) were forced at the boundaries by ERA-Interim reanalysis (Dee et al., 2011) every 6 hours. The ERA-Interim atmospheric model and reanalysis system uses cycle 31r2 of ECMWF's Integrated Forecast System (IFS), and has 60 levels in the vertical and a 
spatial resolution of $0.7^{\circ} \times 0.7^{\circ}$.

The climate change response is determined by comparing the historical present-day simulation (50-year periods, 1951-2000) and the future climate simulations (2001-2050), forced by 3 different Global Climate Models (GCMs) of the IPCC-AR4 (Table 2) forced by various emission scenarios.

The use of the models HDQ03 and HDQ16 allows us to explore the uncertainty associated with the perturbation of the physical parameters in the GCM, using two configurations, Q03 for low sensitivity to global temperature and Q16 for high sensitivity.

Methodology

To evaluate the interannual variability we have calculated the coefficient of variation (CV) with the data of monthly accumulated solar radiation at the surface (rsds). This coefficient removes the dimensionality of the variables by considering the ratio between the standard deviation and the mean. A low value of this ratio shows a high concentration of data around the mean.

We also analyse the variability with the speed of convergence, defined as the number of years in which the anomaly (difference between each year and the average climate value) is lower than $3 \%$. For its calculation we assume that the annual average calculated from all years in the dataset is not significantly different from the climatological value (Gueymard et al., 2011). A high value of this coefficient indicates that we have a greater number of years with low value of anomaly and therefore the variable at that grid point has a low temporal variability.

In addition, to validate the models we calculate the spatial and temporal correlation between the satellite variable SIS and the variable of RCMs, rsds, with the coefficient of Pearson. This coefficient measures the level of relationship between two fields. The range of the coefficient varies between -1 and 1 . As we are comparing modelled values to observations, a good reproduction of solar radiation in the simulations will be characterized by positive values near 1 .

\section{Results}




\section{Validation}

In this first part we evaluate the model biases with respect to observations, so that they can be considered in the second part of the article where we study the climate change signal in various emission scenarios.

Fig. 1 shows the average value of the accumulated annual solar radiation at the surface, detected by the satellite (SIS) and calculated by the $5 \mathrm{RCMs}$ (rsds). The minimum values for observed radiation are located in the northern coast and the maximum in the south of IP. Note the relative maximum in the Ebro valley, which is characterized by a dry climate. Among the models, the lowest simulated values appear in UAHE and the highest in the two UCAN model versions. The UCLM and UMU models show values nearer to observations. The biggest differences are in mountainous areas and especially in the Pyrenees. There is also an important difference in the orientation of the isolines over the south of IP and in the excess irradiation shown by the models over the southeast (fig. A3). If we calculate the difference between SIS and rsds (fig. A1), the two UCAN models show positive biases $\left(100-300 \mathrm{kWh} \cdot \mathrm{m}^{-2}\right)$, the largest differences being in the east. UMU and UAHE show predominantly a negative bias except in Pyrenees and Cantabria where it is positive. UCLM presents a positive bias in the NE and Sierra Nevada and negative in the rest. An analysis of the seasonal bias (Fig. A.2) reveals a consistent pattern of positive (or less negative) biases for mountainous areas and the northern coast, and in general more positive biases in spring and summer, and more negative biases in autumn and winter.

The observed interannual variability of annual accumulated solar radiation at the surface, measured through the $\mathrm{CV}$, shows low values over the IP, with values between 0.02 and 0.04 over most of the area (Fig. 2). This indicates that the solar power resource is very reliable in annual terms, particularly when compared to other renewable energy resources like precipitation (Gil et al., 2015). The largest values are found in the Pyrenees, the northern coast and the southeast. The simulations reproduce the higher variability in the northern coast. For UAHE model, the CV has similar values to CM-SAF, but without the southeastern maximum. UCAN model shows also a negative bias in the southeast (fig. A4). Both 
models underestimate the CV in the Pyrenees. On the other hand, UCLM and UMU show higher values of $\mathrm{CV}$ and generally have a positive bias in relation to CM-SAF, with the maximum positive bias in the northwest. Despite the differences among the models, all coincide in simulating low variability values.

If we analyze the seasonal bias of CV (Fig. A.5), we can see that the models tend to overestimate it in autumn and winter and to underestimate it in spring and summer. The largest negative biases are found in the Pyrenees area. In the western part of IP, the CV is overestimated for almost all models and seasons, in coincidence with the modelled behaviour over the Atlantic Ocean.

Fig. 3 shows the convergence speed. This index indicates the number of years in which solar radiation value differs from average climate value by $3 \%$ or less. High values of the convergence speed indicate also that less years of observed data are needed to characterize the solar resource properly. As our validation period is 20 years, this rate will range from 0 to 20 . The observations show convergence speed values around 10 in the $\mathrm{N}$ and SE, while in the rest of IP it is over 15 years, meaning that in over $75 \%$ of the years the anomaly is lower than $3 \%$. The maximum values are located in the Gulf of Cadiz and the Ebro valley. UCLM and UMU simulate convergence speed values generally lower than CM-SAF, in accordance to their tendency to overestimate the observed temporal variability. In contrast, UAHE and UCAN generally overestimate the observed values, reaching maximum values of 20 years, indicating that the simulated anomaly in these points is always below $3 \%$

Here we propose a classification of gridpoints in terms of the quality of solar energy resource, in which the gridpoints are classified in four categories depending on the combination of solar irradiation amount and variability. The categories or quadrants are obtained dividing in two halves the observed range of solar irradiation and CV over the IP. In Figure 4 we have represented the scatter-plot of these two variables for all land points in the IP, for the different RCMs, observations of CM-SAF and the ensemble of 5 RCMs. There is a high accumulation of points in the lower-right quadrant, which is the optimal combination for solar energy applications: high amount of solar radiation and low variability. Table 3 shows the percentage of points which belong to each quadrant. The high concentration of points in the 
lower-right quadrant is reproduced by the models, though most of them show a lower fraction of values in this quadrant, underestimating the number of optimal gridpoints for solar energy uses. The reason for this bias is different depending on the model: UAHE overestimates the fraction of points in the lower-left quadrant, i.e. the main reason is a negative bias of the irradiation, while UCLM and UMU overestimate the fraction in the upper-right quadrant, which means that they show a positive variability bias. The two versions of UCAN model overestimate the fraction of points in the lower-right quadrant. The ensemble mean is remarkably near to the observed fractions.

We can see where the points for the different quadrants lie by comparing Figures 1 and 2 . The northern coast is the area receiving less radiation and is also one of the areas with higher variability, thus being a relatively less suitable area for the installation of solar plants. Its extension is relatively small, which explains the small fraction of points in the upper-left quadrant of Figure 4. Most of the points to the south of that area combine relatively high irradiation with low variability, explaining the large fraction of points in the lower-left quadrant. The areas with the best combined values are found in the southwestern part, which is therefore an area with a high and reliable solar energy resource. These results are consistent with those obtained by Gil et al. (2015).

Fig. 5 shows the temporal correlations of the $5 \mathrm{RCMs}$ and the ensemble mean with respect to observations. The northern mountainous areas of IP are the ones with a lower correlation coefficient according to all models, while there are differences among them in the location of higher values. For UAHE and UMU the maximum correlations are located in the SW, while for UCLM and UCAN models they are located in the SE of the IP. A noteworthy aspect is that high temporal correlation can be found for areas with important biases, like the eastern areas of the IP for UCAN, indicating that model biases may not be related with model variability. In the ensemble mean we can see high correlation values along the entire Mediterranean coast and lower correlation values near the Atlantic coasts.

Table 4 shows the value of temporal and spatial correlation for the whole domain. In this estimation we 
have only taken into account the domain cells belonging to the Iberian Peninsula and the Balearic Islands, while the cells belonging to sea, Africa and France were discarded. In both cases the correlation of the ensemble mean is high, but not the highest. Spatial correlation values are always above 0.85 indicating that the spatial distribution of radiation is well captured by the simulations. The temporal correlation is lower, but still rather high, around 0.65 , significant at $99 \%$ for all models. Models with higher spatial correlation show lower temporal correlation, and vice versa. An interesting result is found for the two different versions of UCAN model, as for both types of correlation the model version A has lower values than B. Version B includes a more complex (non-local) parameterization of the planetary boundary layer (Jiménez-Guerrero et al., 2013), which can indicate that the simulation of spatial and temporal variations of solar radiation is affected by boundary layer processes. The table also shows the bias and RMSE of the models with respect to satellite observations. We can see clearly the model with the smallest errors is UCLM, which shows the best values in 3 of the 4 indexes. It is also interesting to see that the ensemble mean shows lower RMSE and bias than any of the models, but not the highest correlations.

\section{Future scenarios}

In this second part we analyse future climate projections downscaled by one of the RCM models (UCLM), for different emission scenarios (B1, A1B and A2) and 3 different nesting GCMs. We have used the regional climate model UCLM for two reasons. The first is that it is the model with the lowest bias and RMSE compared to satellite observations, and it shows the highest temporal correlation (see Table 4). The second reason is that this model has been nested in all the available GCM scenario simulations, unlike other models.

First, we study the projected time-averaged changes of annual solar irradiation. These changes and their statistical significance are shown in Figure 6. The predominant change is a radiation increase in the period 2001-2050 compared to 1951-2000, and significant changes are almost totally positive. In 4 of the 7 scenarios there are extended areas of statistically significant increase (up to more than $60 \mathrm{kWh} / \mathrm{m}^{2}$ ). These

4 scenarios correspond to simulations with ARPEGE, HDQ03 and HDQ16 GCMs. In the other 3 
scenarios, which have been obtained with a different GCM (EC5R2), the projected changes are much smaller, with areas of increase and areas of decrease, and most of them are not significant. The contrast between nesting GCMs indicates that the uncertainty due to GCM formulation is important, more than the uncertainty linked to the emissions scenario. There is no clear coincidence between simulations for the same emissions scenario, and no tendency can be discerned with increasing emissions (from B1 to A2 scenarios). This may be probably associated with the fact that precipitation changes do not show either any clear tendency with increasing emissions in the period considered, as clear signals for precipitation changes tend to appear only in the second half of the century (Jacob et al., 2014; Sillmann et al., 2013; Kharin et al., 2007).

The spatial distribution of the changes shows a rather systematic maximum in southwestern IP (6 out of 7 simulations show this). The minimum change values (which are even negative in some simulations, though not statistically significant) are found in the mountainous areas of the north and in the southeast, in most simulations. The main exception to this behaviour is the A2 scenario simulation nested in EC5R2, which shows a decrease in the southern and central IP together with a (statistically significant) increase in the north.

In Fig. 7 the projected change in the coefficient of variability (CV) is shown. The general pattern followed by most of the simulations consists in a negative change (less variability) in a broad northeastern area and a positive change (more variability) in the southwestern part of IP. But this geographic pattern has two exceptions. The simulation nested in HDQ3 shows an inverse pattern (more variability in the northeast and less in the southwest), while the simulation for A2 scenario nested in EC5R2 is dominated by negative changes except for small areas in the north and south of the peninsula. There seems to be no systematic relationship between the change in annual irradiation and the change in interannual variability. For example, the increase in annual irradiation (of more than $60 \mathrm{kWh} \cdot \mathrm{m}^{-2}$ ) found in the western part in the A1B simulation nested in ARPEGE is associated to a decreased variability in the northwest and to an increased variability in the southwest. 
Table 5 shows the spatially-averaged change of solar irradiation and interannual variability for the Iberian Peninsula in the different scenarios compared to the control scenario. An increase in surface irradiation is found on average for the whole IP in most simulations, with the smallest changes corresponding to the three scenarios nested in EC5R2. The latter result is consistent with the lack of statistical significance in the spatial distribution of the changes (Fig. 6). In contrast, the largest average changes of the variability (with opposite sign) are found in two of the EC5R2 simulations. This reflects the absence of a clear relationship between the change in irradiation and the change in variability.

The combined changes of irradiation amount and variability are presented in the scatter-plots of Fig. 8. In most scenarios, a future increase in the variability is found for points with high present irradiation values. This variability increase is associated to a higher spread, which indicates larger differences in variability between different points in IP. There are two exceptions, for the same scenarios that showed a different behaviour in Fig. 7. In HDQ03-A1B scenario there is less spread in the variability values, together with some tendency towards a reduction in variability for points with low irradiation values. EC5R2-A2 shows a variability reduction for the whole range of irradiation values. These two scenarios show a CV decrease over the southwestern part of the IP, in contrast to the other ones.

In terms of the quadrants of Fig. 8, there is a clear shift in most scenarios from the lower-right quadrant (high irradiation/low variability) to the upper-right quadrant (high irradiation/high variability). This implies some loss of quality in the solar resource, but it should be taken into account that the quadrants are relative to the observed ranges in IP, which are not particularly large. In any case, even including this shift more than $50 \%$ of the points should remain in the optimal lower-right quadrant (there is only one exception, ARPEGE-A1B scenario, in which this percentage diminishes to 43\%). Interestingly, in the two scenarios with a different future evolution (HDQ03-A1B and EC5R2-A2) the percentage of points in the optimal quadrant increases to high values ( $70 \%$ and $73 \%$, respectively), pointing towards higher quality of the solar resource in IP. This contrasting result can be associated to the different evolution over the south-southwestern part of the IP, where CV is projected to increase in most simulations except those two (see Fig. 7). 
Finally, we have made a first analysis of the future ability of solar resource to cover high energy demand periods in summer, which will occur due to above-average temperatures and the associated increase of air-conditioning. We have calculated the temporal correlation (Pearson coefficient) of monthly anomalies of $2 \mathrm{~m}$ temperature and solar irradiation in summer, in order to focus on extended periods of higher-thannormal temperatures. The considered period is 2001-2050. The last column of Table 5 shows the value of the correlation coefficient $\mathrm{R}$ between the spatially-averaged anomalies, while Fig. 9 shows the spatial distribution of the correlation coefficient. Spatially-averaged values are rather high and fairly similar among the different scenarios, ranging from 0.57 to 0.68 . But the spatial distribution shows important differences between regions. Particularly over central and southern parts of IP, the correlation is lower (about 0.4-0.5), while higher values (about 0.6-0.7) are found over areas near to the northwestern and northern coasts. The Ebro valley in the northeast shows consistently relatively low values, in contrast to the relatively high values over mountainous areas in the east. The overall spatial patterns seem to depend more on the nesting GCM than on the emissions scenario. In summary, a clear local solar irradiation response to locally higher temperatures would occur only in some regions, but on an aggregated level there should be an increase of solar energy resource in periods with higher temperatures over the whole IP.

\section{Conclusions}

In this study, we have analysed the impact of climate change on surface solar irradiation over the Iberian Peninsula (IP). This type of study is important because solar energy can play a decisive roll in the future electrical production. We make use of simulations from ESCENA project (Jiménez-Guerrero et al., 2013), that are particularly adequate for studies over the IP as the domains of the RCMs are centered on it and extend much more towards the west than data from other multi-model downscaling experiments like EUROCORDEX or MedCORDEX.

Simulations nested in ERA-Interim reanalysis (evaluation runs) are compared to observations (CM SAF 
satellite data). The main differences between the models and the satellite in terms of annual solar irradiation are found in mountainous areas. Most models simulate the maximum gradient of solar irradiation along a northwest to southeast axis, instead of the observed overall north to south gradient. The biases are very different among the RCMs. Interestingly, the model with the highest RMSE and bias values (UAHE) shows the best spatial distribution, as reflected by a spatial correlation of 0.94 . The relatively high interannual variability values in the north are well captured by the models, while the other observed variability maximum near the Mediterranean coast is only reproduced by some of them. This could be related to the large differences between models in the representation of precipitation (and therefore clouds) over the Mediterranean regions of IP (Domínguez et al., 2013). The strong variability contrast between the Pyrenees mountain range and the Ebro valley south of it is rather well reproduced in the simulations. Some models also overestimate the variability near the western coast. But overall, the low observed interannual variability is rather well captured in general. This aspect is important, as it makes solar energy a very reliable source in terms of annual production.

Another diagnostic to characterize the interannual stability of the solar resource is the convergence speed (Gueymard and Wilcox, 2011), which indicates the number of years in which solar irradiation differs from average climate values by $3 \%$ or less. Less years of observed data are needed to characterize the solar resource if the convergence speed is high. The observed convergence is high over most of IP, except in the north and southeast. The contrasts in the simulation of interannual variability are reflected in biases of different sign for the convergence speed in the RCMs.

We make a combined assessment of the amount and variability of solar irradiation. Dividing the observed range of solar irradiation and the CV over the IP in two halves, we classify the gridpoints in four quadrants. The quadrant with the highest resource quality combines high solar irradiation with low variability, while the quadrant with the lowest resource quality combines low solar irradiation with high variability. In the observations, most of the points (81\%) of the IP are in the best quadrant, showing therefore an optimal combination for solar energy applications. Geographically, the best quality points are in the southwestern part of the IP. The evaluation runs of most RCMs are able to reproduce a concentration of points in the optimal quadrant, though there is some tendency in the simulations to 
overestimate the weak relationship found in observations between increasing irradiation and decreasing variability. The multi-model ensemble mean is very near to the observations, indicating that the model biases are of opposite sign.

In the second part of this study we have characterized the impact of the climatic change on solar irradiation in the IP. For this goal we have used only the simulations of the UCLM RCM as it is the one that shows the best values in most skill scores and also has been nested in all the available GCM scenario simulations. In the downscaled scenarios, the predominant change is an increase in annual solar irradiation, although both the geographical distribution and the degree of statistical significance is very different between simulations. There is no definite trend of irradiation changes with increasing emissions, which is probably due to the fact that differences in emissions and concentrations of greenhouse gases are beginning to be clearly noticeable only after mid-century. The differences associated to the nesting GCM are greater than the differences due to the emission scenario used. Regarding the change in interannual variability, most simulations show an overall pattern that consists in a negative change (less variability) in a broad northeastern area and a positive change (more variability) in the southwestern part of IP. But there are two exceptions to this projected change. The simulation nested in HDQ3 shows an inverse pattern (more variability in the northeast and less in the southwest), while the simulation nested in EC5R2-A2 scenario is dominated by negative changes. There seems to be no systematic relationship between the change in annual irradiation and the change in interannual variability.

The combined assessment of solar irradiation amount and variability indicates that in most projections, a future increase in the variability is found for points with high present irradiation values, with a clear shift from the optimal quadrant (high irradiation/low variability) towards the quadrant with high irradiation/high variability. This points to a certain quality loss in the solar resource, but it should be taken into consideration that the classification of irradiation quality in quadrants is relative to the observed ranges of solar irradiation amount and variability in IP, which are not particularly large. Not all the scenarios follow this behavior, as in two of them the percentage of points in the optimal quadrant increases, pointing towards an enlargement of the area with a high quality of the solar resource in the IP. These two scenarios are characterized by a CV decrease over the southwestern part of the IP, in contrast 
to the other ones. These exceptions are not linked to a particular GCM or emissions scenario.

Finally, we have made a first approximation to the issue of the future ability of solar energy to cover power demand peaks due to high summer temperatures. The response of local solar irradiation to abovenormal temperatures in summer months differs between regions. The correlation between both variables is rather high near the northern coasts and over the eastern mountains, while in central and southern parts lower, but still positive, correlations are found. On an aggregated level the correlation is rather high, indicating that spatially averaged solar irradiation should increase clearly when spatially averaged temperatures are above the mean value. This is a positive result as the power grid is strongly interconnected within IP, which could allow a distribution of possible surpluses of solar power between different peninsular regions.

\section{Acknowledgements}

The work performed was done by using data from EUMETSAT's Satellite Application Facility on Climate Monitoring (CM SAF). TL is supported with funds from the MINECO under the Juan de la Cierva-Incorporación Programme (IJCI-2015-26645).

\section{References}

Bartos MD, Chester MV. 2015. Impacts of climate change on electric power supply in the Western United States. Nature Climate Change 5(8): 748-752. doi:10.1038/nclimate2648.

Burnett D, Barbour E, Harrison G. 2014. The UK solar energy resource and the impact of climate change. Renewable Energy 71: 333-343. doi:10.1016/j.renene.2014.05.034.

Castro M, Fernández C, Gaertner MA. 1993. Description of a mesoscale atmospheric numerical model. 
In: Díaz JI, Lions JL (eds) Mathematics, climate and environment. Rech Math Appl Ser 27, Masson, Paris, p 230-253.

Christensen JH, Christensen OB. 2007. A summary of the PRUDENCE model projection of changes in European climate by the end of this century. Clim Change 81:7-30. doi: 10.1007/s10584-006-9210-7.

Collins M, Booth B, Harris G, Murphy J, Sexton D, Webb M. 2006. Towards quantifying uncertainty in transient climate change. Climate Dyn 27: 127-147. doi: 10.1007/s00382-006-0121-0.

Crook JA, Jones LA, Forster PM, Crook R. 2011. Climate change impacts on future photovoltaic and concentrated solar power energy output. Energy \& Environmental Science 4(9): 3101-3109. doi:10.1039/C1EE01495A.

Dee DP, Uppsala SM, Simmons AJ, Berrisford P, Poli P, Kobayashi S, Andrae U, Balmaseda MA, Balsamo G, Bauer P, Bechtold P, Beljaars ACM, van de Berg L, Bidlot J, Bormann N, Delsol C, Dragani R, Fuentes M, Geer AJ, Haimberger L, Healy SB, Hersbach H, Hólm EV, Isaksen L, Kållberg P, Köhler M, Matricardi M, McNally AP, Monge-Sanz BM, Morcrette J-J, Park B-K, Peubey C, de Rosnay P, Tavolato C, Thépaut J-N, Vitart F. 2011. The ERA-Interim reanalysis: configuration and performance of the data assimilation system. Q. J. R. Meteorol. Soc. 137: 553-597. doi: 10.1002/qj.828.

Domínguez M, Gaertner MA, de Rosnay P, Losada T. 2010. A regional climate model simulation over West Africa: parameterization tests and analysis of land surface fields. Climate Dynamics 35: 249-265. doi: 10.1007/s00382-010-0769-3.

Domínguez M, Romera R, Sánchez E, Fita L, Fernández J, Jiménez-Guerrero P, Montáve JP, Cabos WD, Liguori G, Gaertner MA. 2013. Present-climate precipitation and temperature extremes over Spain from a 
set of high resolution RCMs. Climate Research, 58(2): 149-164. doi: https://doi.org/10.3354/cr01186.

Dosio A. 2016. Projections of climate change indices of temperature and precipitation from an ensemble of bias-adjusted high-resolution EURO-CORDEX regional climate models. J. Geophys. Res. Atmos. 121: 5488-5511. doi:10.1002/2015JD024411.

Fita L, Fernández J, García-Díez M. 2010. CLWRF: WRF modifications for regional climate simulation under future scenarios. Proc 11th WRF Users' Workshop, Boulder, CO.

Gaetani M, Huld T, Vignati E, Monforti-Ferrario F, Dosio A, Raes F. 2014. The near future availability of photovoltaic energy in Europe and Africa in climate-aerosol modeling experiments. Renewable and Sustainable Energy Reviews 38: 706-716. doi: https://doi.org/10.1016/j.rser.2014.07.041.

Gil V, Gaertner MA, Sanchez E, Gallardo C, Hagel E, Tejeda C, Castro M. 2015.Analysis of interannual variability of sunshine hours and precipitation over Peninsular Spain. Renewable Energy 83: 680-689. doi: http://dx.doy.org/10.1016/j.renene.2015.05.001.

Gómez G, Cabos WD, Liguori G, Sein D, Lozano-Galeana S, Fita L, Fernández J, Magariño ME, Jiménez-Guerrero P, Montávez JP, Domínguez M, Romera R, Gaertner MA. 2016. Characterization of the wind speed variability and future change in the Iberian Peninsula and the Balearic Islands. Wind Energ. 19: 1223-1237. doi: 10.1002./we.1893.

Gómez-Navarro JJ, Montávez JP, Jerez S, Jiménez-Guerrero P, Lorente-Plazas R, González-Rouco JF, Zorita E. 2011. A regional climate simulation over the Iberian Peninsula for the last millennium. Clim. Past 7: 451-472. doi: https://doi.org/10.5194/cp-7-451-2011.

Grell G, Dudhia J, Stauffer DR. 1994. A description of the fifth-generation Penn State/NCAR mesoscale model (MM5). National Center for Atmospheric Research. Technical Note, TN-398+STR. 
Gueymard CA, Wilcox SM. 2011. Assessment of spatial and temporal variability in the US solar resource from radiometric measurement and predictions from models using ground-based or satellite data. Solar Energy 85: 1068-1084. doi: https://doi.org/10.1016/j.solener.2011.07.004.

Gueymard CA. 2012. Temporal variability in direct and global irradiance at various timescales as affected by aerosols. Sol Energy 86: 3544-53. doi: http://dx.doi.org/10.1016/j.solener.2012.01.013.

Gunderson I, Goyette S, Gago-Silva A, Quiquerez L, Lehmann A. 2015. Climate and land-use change impacts on potential solar photovoltaic power generation in the Black Sea region. Environmental Science \& Policy 46: 70-81. doi: 10.1016/j.envsci.2014.04.013.

Gutowski WJ, Takle ES, Kozak KA, Patton JC, Arritt RW, Christensen JH. 2007. A Possible Constraint on Regional Precipitation Intensity Changes under Global Warming. J. Hydrometeor., 8: 1382-1396. doi: https://doi.org/10.1175/2007JHM817.1

Jacob D, Van den Hurk BJJM, Andrae Ulf, Elgered G, Fortelius C, Graham LP, Jackson SD, Karstens U, Köpken Chr, Lindau R, Podzun R, Rockel B, Rubel F, Sass BH, Smith RNB, Yang X. 2001. A comprehensive model inter-comparison study investigating the water budget during the BALTEXPIDCAP period. Meteorol. Atmos. Phys. 77: 19-43.

Jacob D, Petersen J, Eggert B, Alias A, Christensen OB, Bouwer LM, Braun A, Colette A, Déqué M, Georgievski G, Georgopoulou E, Gobiet A, Menut L, Nikulin G, Haensler A, Hempelmann N, Jones C, Keuler K, Kovats S, Kröner N, Kotlarski N, Kriegsmann A, Martin E, van Meijgaard E, Moseley C, Pfeifer S, Preuschmann S, Radermacher C, Radtke K, Rechid D, Rounsevell M, Samuelsson P, Somot S, Soussana JF, Teichmann C, Valentini R, Vautard R, Weber B, Yiou P. 2014. EURO-CORDEX: new highresolution climate change projections for European impact research. Reg Environ Change 14: 563-578. doi: 10.1007/s10113-013-0499-2. 
Jerez S, Montávez JP, Jiménez-Guerrero P, Gómez-Navarro JJ, Lorente-Plazas R, Zorita E. 2012. A multiphysics ensemble of present-day climate regional simulations over the Iberian Peninsula. Clim. Dyn. 40: 3023-3046. doi: 10.1007/s00382-012-1539-1.

Jerez S, Montávez JP, Gómez-Navarro JJ, Lorente-Plazas R, García-Valero JA, Jiménez-Guerrero P. 2013. A multiphysics ensemble of regional climate change projections over the Iberian Peninsula. Clim. Dyn. 41: 1749-1768. doi: 10.1007/s00382-012-1551-5.

Jerez S, Tobin I, Vautard R, Montávez JP, López-Romero JM, Thais F, Bartok B, Christensen OB, Colette A, Déqué M, Nikulin G, Kotlarski S, Van Meijgaard E, Teichmann C, Wild M. 2015. The impact of climate change on photovoltaic power generation in Europe. Nature Communications 6, 10014. doi:10.1038/ncomms10014.

Jiménez-Guerrero P, Montávez JP, Domínguez M, Romera R, Fita L, Fernández J, Cabos WD, Liguori G, Gaertner MA. 2013. Mean fields and interannual variability in RCM simulations over Spain: the ESCENA project. Clim. Res. 57: 201-220. doi:10.3354/cr01165

Jungclaus J, Keenlyside N, Botzet M, Haak H, Luo J, Latif M, Marotzke J, Mikolajewicz U, Roeckner E. 2006. Ocean circulation and tropical variability in the coupled model ECHAM5/MPI-OM. J. Climate 19: 3952-3972. doi:https://doi.org/10.1175/JCLI3827.1

Kharin VV, Zwiers FW, Zhang X, Hegerl GC. 2007. Changes in Temperature and Precipitation Extremes in the IPCC Ensemble of Global Coupled Model Simulations. J. Climate, 20: 1419-1444. doi: https://doi.org/10.1175/JCLI4066.1.

Klemp JB, Skamarock WC, Dudhia J. 2007. Conservative split-explicit time integration methods for the compressible non-hydrostatic equations. Mon. Weather Rev. 135: 2897-2913. 
doi:https://doi.org/10.1175/NWR3440.1.

Knutti R, Furrer R, Tebaldi C, Cermak J, Meehl GA. 2010. Challenges in combining projections from multiple climate models. J. Clim. 23: 2739-2758. doi:https://doi.org/10.1175/2009JCLI3361.1

van der Linden P, Mitchell JFB. 2009. ENSEMBLES: Climate Change and its impacts: Summary of research and results from the ENSEMBLES project. Tech. rep., Met Office Hadley Centre, Exeter, UK.

Pašičko R, Branković Č, Šimić Z. 2012. Assessment of climate change impacts on energy generation from renewable sources in Croatia. Renewable Energy 46: 224-231. doi: https://doi.org/10.1016/j.renene.2012.03.029

Panagea IS, Tsanis IK, Koutroulis AG, Grillakis MG. 2014. Climate Change Impact on Photovoltaic Energy Output: The Case of Greece. Advances in Meteorology 2014, Article ID 264506, 11 pages. doi:10.1155/2014/264506

Patt A, Pfenninger S, Lilliestam J. 2013. Vulnerability of solar energy infrastructure and output to climate change. Climatic change 121(1): 93-102. doi: http://dx.doi.org/10.1007/s10584-013-0887-0.

Räisänen J, Hansson U, Ullerstig A, Döscher R, Graham LP, Jones C, Meier HEM, Samuelsson P, Willén U. 2004. European climate in the late twenty-first century: regional simulations with two driving global models and two forcing scenarios. Climate Dynamics 22: 13-31. doi: 10.1007/s00382-003-0365-x.

Rowell DP. 2005. A scenario of European climate change for the late twenty-first century: seasonal means and interannual variability. Climate Dynamics 25: 837-849. doi: 10.1007/s00382-005-0068-6. 
Salas-Mélia D, Chauvin F, Déqué M, Douville H, Guérémy J, Marquet P, Planton S, Royer J, Tyteca S. 2005. Description and validation of the CNRM-CM3 global coupled model. CNRM working note 103.

Sillmann J, Kharin VV, Zwiers FW, Zhang X, Bronaugh D. 2013. Climate extremes indices in the CMIP5 multimodel ensemble: Part 2. Future climate projections. J. Geophys. Res. Atmos., 118: 2473-2493. doi:10.1002/jgrd.50188.

Skamarock WC, Klemp JB, Dudhia J, Gill DO, Barker DM, Duda MG. 2008. A description of the Advanced Research WRF version 3. NCAR Tech Note NCAR/ TN 20201 c475+STR, available at www.mmm. ucar. edu/ wrf/ users/ docs/arw v3.pdf

Tobin I, Vautard R, Balog I, Bréon FM, Jerez S, Ruti PM, Thais F, Vrac M, Yiou P. 2015. Assessing climate change impacts on European wind energy from ENSEMBLES high-resolution climate projections. Climatic Change 128: 99-112. doi: 10.1007/s10584-014-1291-0

Wild M, Folini D, Henschel F, Fischer N, Müller B. 2015. Projections of long-term changes in solar radiation based on CMIP5 climate models and their influence on energy yields of photovoltaic systems. Solar Energy 116: 12-24. https://doi.org/10.1016/j.solener.2015.03.039 


\begin{tabular}{|c|c|c|c|c|c|}
\hline Model & $\begin{array}{l}\text { Geographical } \\
\text { projection }\end{array}$ & $\begin{array}{l}\text { Number of } \\
\text { vertical levels }\end{array}$ & $\begin{array}{l}\text { Horizontal } \\
\text { resolution }\end{array}$ & $\begin{array}{l}\text { Name in } \\
\text { this study }\end{array}$ & References \\
\hline PROMES & Lambert & 37 & $25 \mathrm{~km}$ & UCLM & $\begin{array}{l}\text { Castro et al. (1993), Domínguez } \\
\text { et al. (2010) }\end{array}$ \\
\hline WRF-A & Lambert & 33 & $25 \mathrm{~km}$ & UCAN-A & \multirow{2}{*}{$\begin{array}{l}\text { Klemp et al. (2007), Skamarock } \\
\text { et al. (2008), Fita et al. (2010) }\end{array}$} \\
\hline WRF-B & Lambert & 33 & $25 \mathrm{~km}$ & UCAN-B & \\
\hline MM5 & Lambert & 30 & $25 \mathrm{~km}$ & UMU & $\begin{array}{l}\text { Gomez-Navarro et al. (2011), } \\
\text { Jerez et al. (2012), Jerez et al. } \\
\text { (2013), Grell et al. (1994) }\end{array}$ \\
\hline REMO & Rotated lat-lon & 31 & $0.22^{\circ}$ & UAHE & Jacob et al. (2001) \\
\hline
\end{tabular}

Table 1: RCM models used in this study.

\begin{tabular}{|l|l|l|l|}
\hline Model & EC5R2 & ARPEGE & HDQ03 and HDQ16 \\
\hline Institution & Max Planck Institute für & CNRM-Météofrance, France & Met Office Hadley \\
& Meteorologie, Germany & & Center, UK \\
\hline Reference & Jungclaus et al. (2006) & Salas-Mélia et al. (2005) & Collins et al. (2006) \\
\hline Atmospheric model & ECHAM5 & ARPEGE C13 & HadAM3 \\
\hline Resolution & T63 L31 & T63 L45 & $3.75^{\circ}$ x2.5 ${ }^{\circ}$ 19 \\
\hline Ocean model & MPI-OM & OPA 8.1 & HadOM3 \\
\hline Emission scenarios & A1B, B1,A2 & A1B, B1 & A1B \\
\hline
\end{tabular}

Table 2: GCM models used in this study. 


\begin{tabular}{|l|c|c|c|c|c|c|c|}
\hline Quadrant & CMSAF & UAHE & UCANA & UCANB & UCLM & UMU & ENSEMBLE \\
\hline Upper-left & 3.00 & 1.21 & 8.18 & 4.86 & 14.57 & 19.55 & 7.54 \\
\hline Upper-right & 0.38 & 0.00 & 0.83 & 0.00 & 9.58 & 2.17 & 0.00 \\
\hline Lower-left & 15.14 & 53.29 & 3.51 & 6.52 & 9.84 & 24.73 & 11.31 \\
\hline Lower-right & 81.47 & 45.50 & 87.48 & 88.63 & 66.01 & 53.55 & 81.15 \\
\hline
\end{tabular}

Table 3: Percentage of points in each quadrant for the RCMs, CM-SAF and the ensemble.

\begin{tabular}{|c|c|c|c|c|}
\hline Models & Spatial & Temporal & RMSE & BIAS \\
& correlation & correlation & $\left(\mathrm{kWhm}^{-2}\right)$ & $\left(\mathrm{kWhm}^{-2}\right)$ \\
\hline UAHE & 0.94 & 0.64 & 152.458 & -141.562 \\
\hline UCAN_A & 0.85 & 0.63 & 144.816 & 124.839 \\
\hline UCAN_B & 0.89 & 0.68 & 141.575 & 130.123 \\
\hline UCLM & 0.86 & 0.69 & 88.184 & -42.310 \\
\hline UMU & 0.89 & 0.60 & 132.176 & -116.273 \\
\hline Ensemble & 0.90 & 0.65 & 63.988 & -9.037 \\
\hline
\end{tabular}

Table 4: Temporal and spatial correlation, rmse and mean bias of solar irradiation for the RCMs and the ensemble mean.

\begin{tabular}{|c|c|c|c|}
\hline & $\begin{array}{c}\text { RSDS CHANGE } \\
\left(\mathrm{kWh} \cdot \mathrm{m}^{-2}\right)\end{array}$ & CV CHANGE & $\mathrm{R}$ \\
\hline ARPEGE- A1B & 23.7 & 0.0018 & 0.65 \\
\hline ARPEGE- B1 & 33.2 & 0.0002 & 0.60 \\
\hline HDQ03-A1B & 42.5 & -0.0025 & 0.66 \\
\hline HDQ16-A1B & 51.3 & 0.0016 & 0.68 \\
\hline EC5R2-B1 & 8.0 & 0.0004 & 0.57 \\
\hline EC5R2-A2 & -2.0 & -0.0031 & 0.65 \\
\hline EC5R2-A1B & 3.5 & 0.0026 & 0.63 \\
\hline
\end{tabular}

Table 5: Change of solar irradiation (rsds) and CV and correlation coefficient $\mathrm{R}$ between the monthly time series of anomalies of the temperature and solar irradiation in summer for the 50 scenario years (2001-2050). 

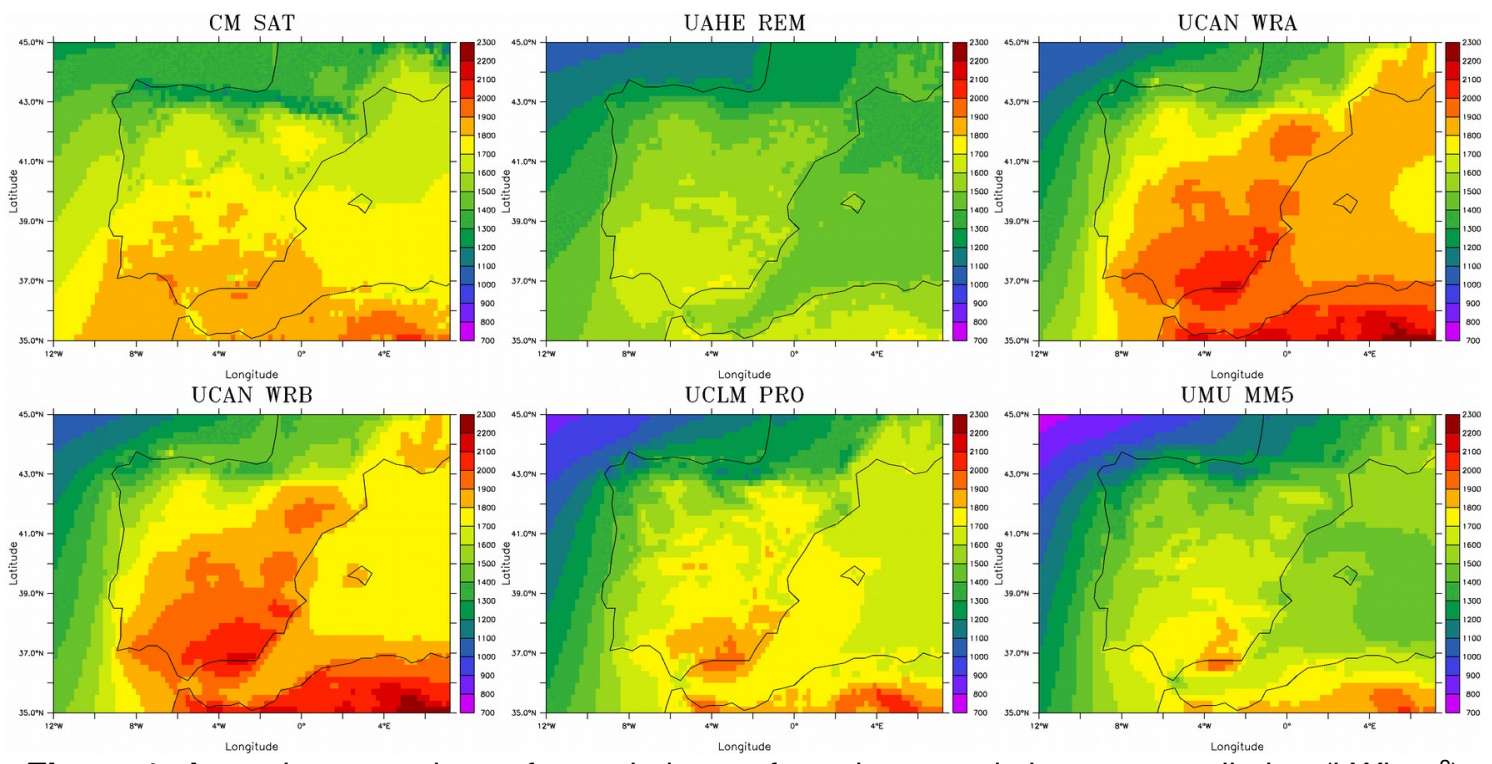

UMU MM5

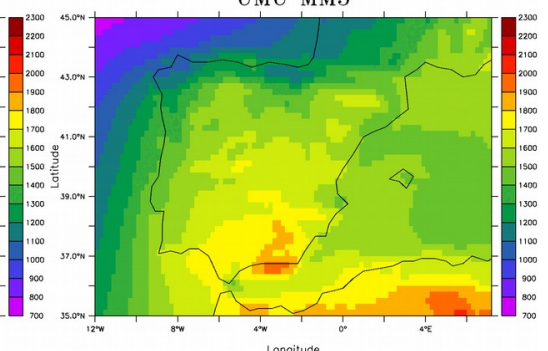

Figure 1: Annual mean values of cumulative surface downward shortwave radiation ( $\left.\mathrm{kWhm}^{-2}\right)$ for the satellite (CM-SAF) and the 5 RCMs.

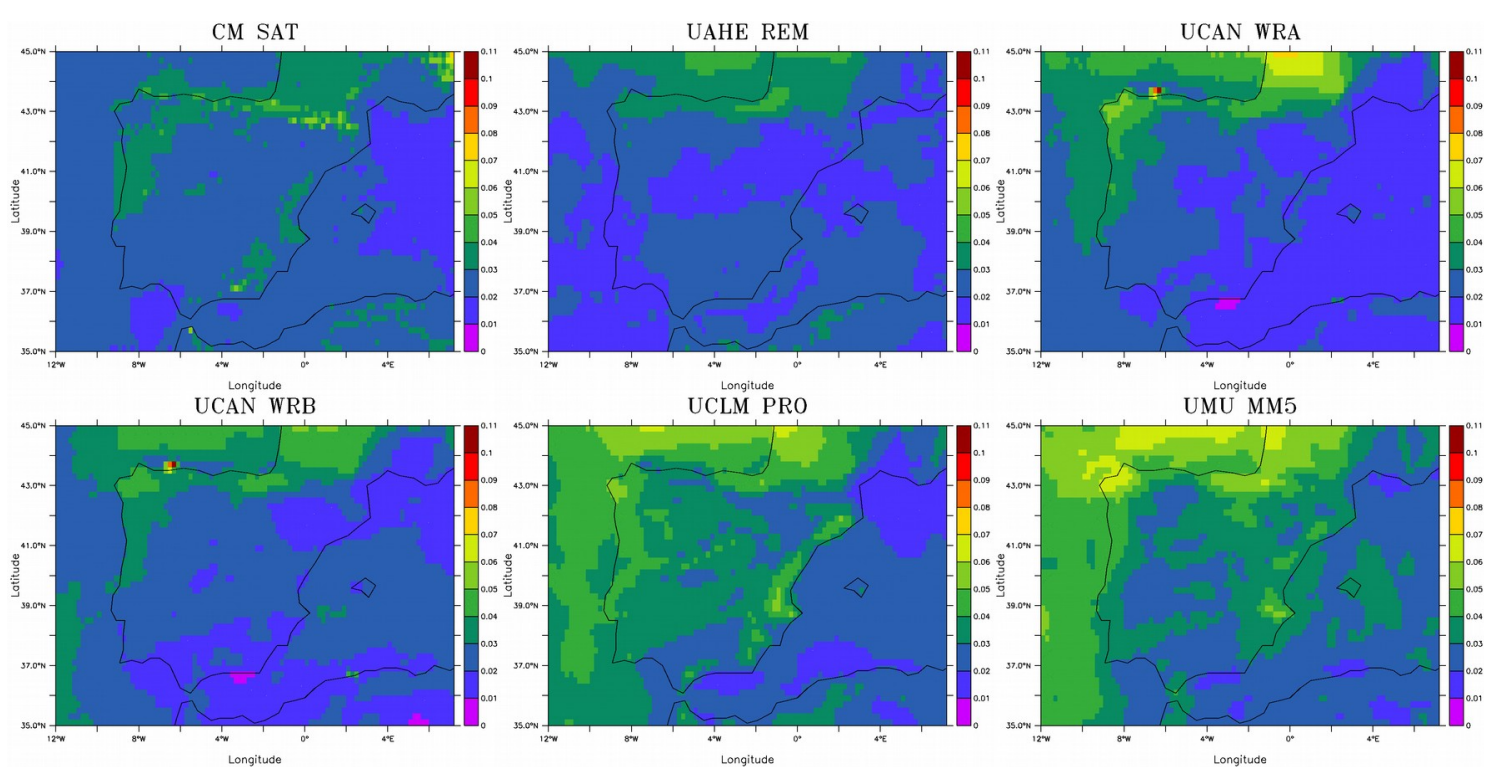

Figure 2: Values of interannual CV of solar irradiation for the satellite (CM-SAF) and the 5 RCMs. 

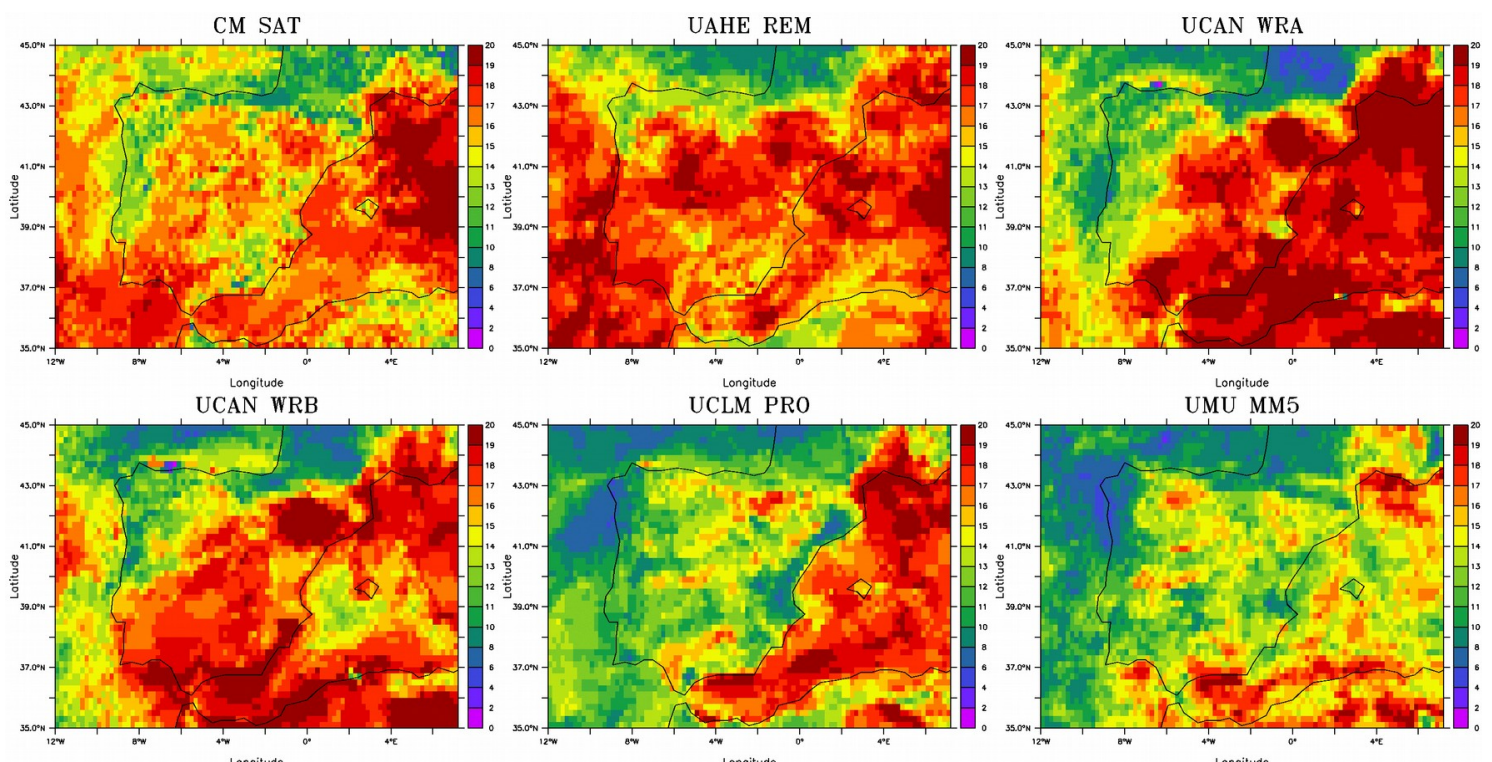

Figure 3: Convergence speed: number of years in the rsds series with an annual anomaly below $3 \%$.

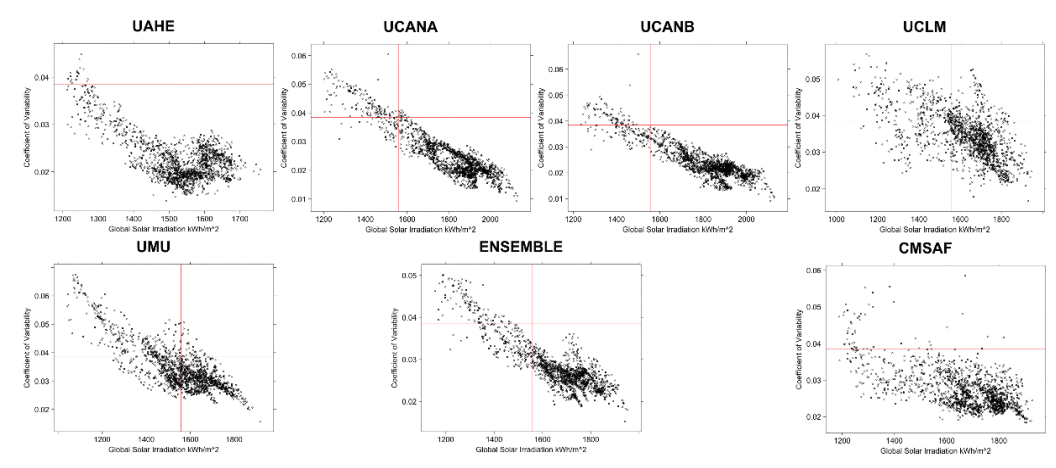

Figure 4: Scatter-plot of the coefficient of variability against solar irradiation at the surface for the 5 RCMs, CM-SAF and the ensemble of the 5 models.

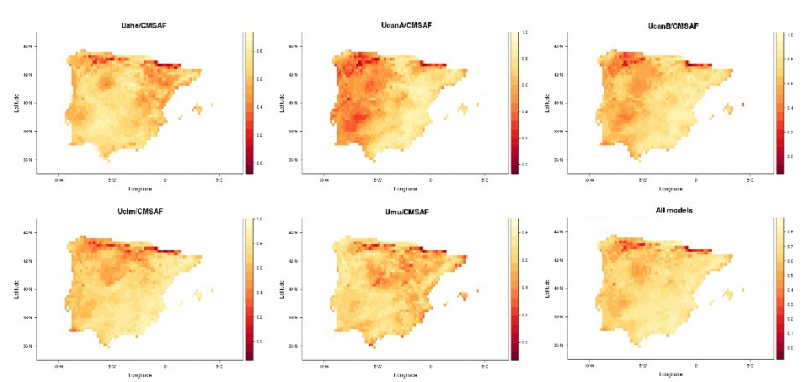

Figure 5: Values of temporal correlation for rsds series for the $5 \mathrm{RCMs}$ and the ensemble of the models. 

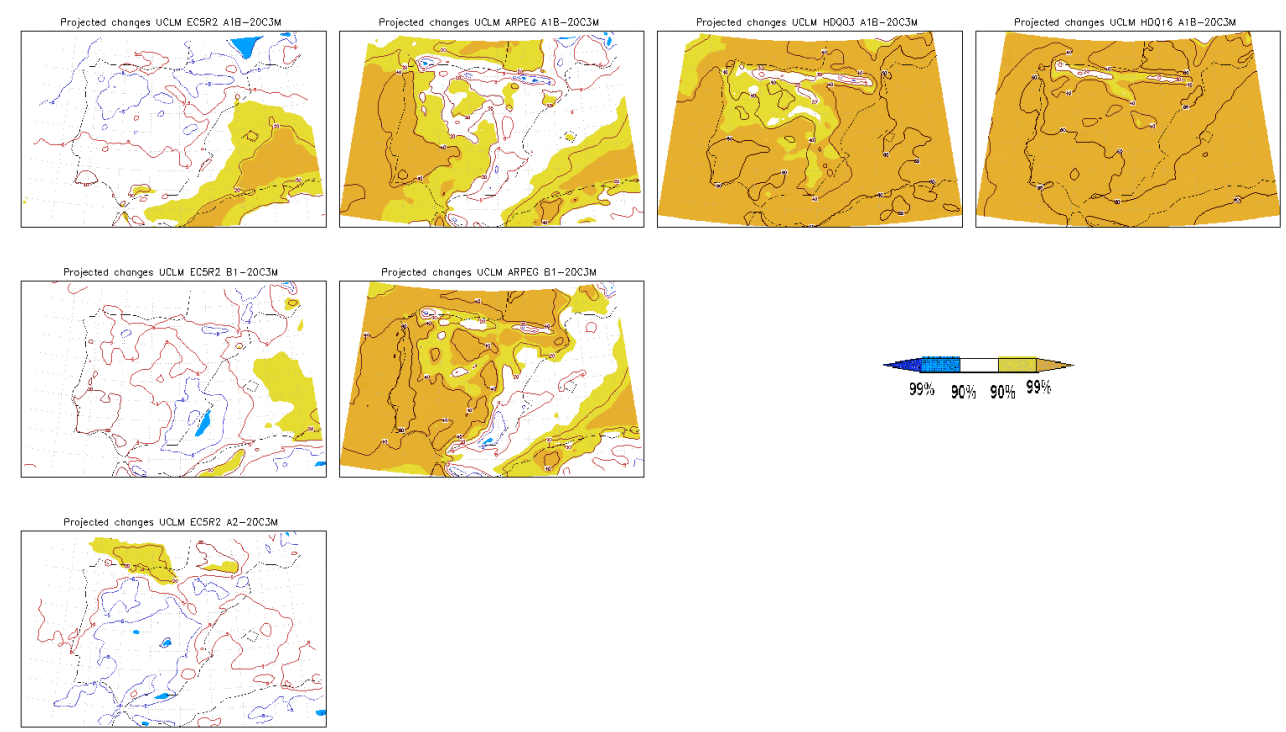

Figure 6: Values of projected change of rsds (contours, red positive, blue negative) for the different scenarios. The colour scale represents the significance level using the t-student test.

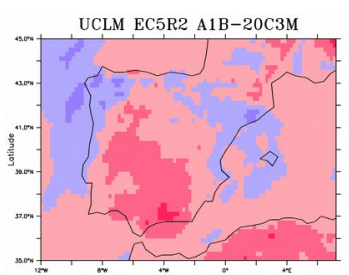

UCLM EC5R2 B B1-20C3M

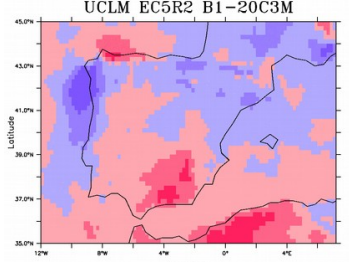

UCLM EC5R2 A2-20C3M

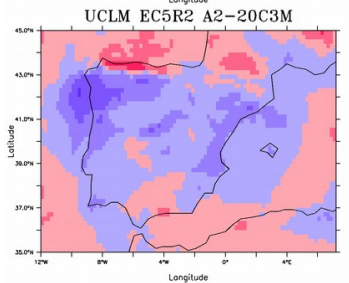

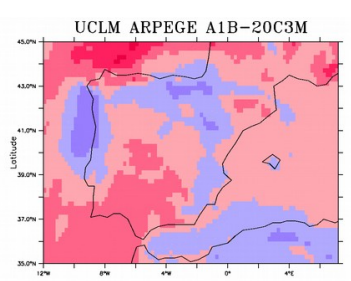

UCLM ARPEGE B1-20C3M
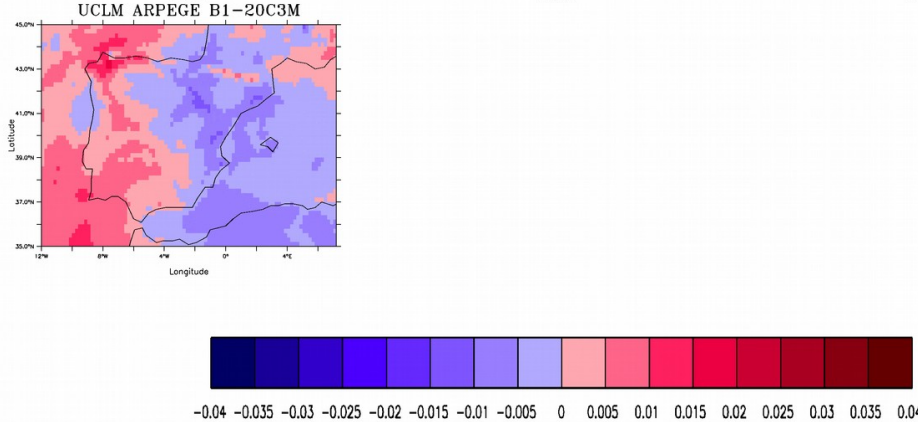

Figure 7: Values of projected change of CV for the different scenarios. 


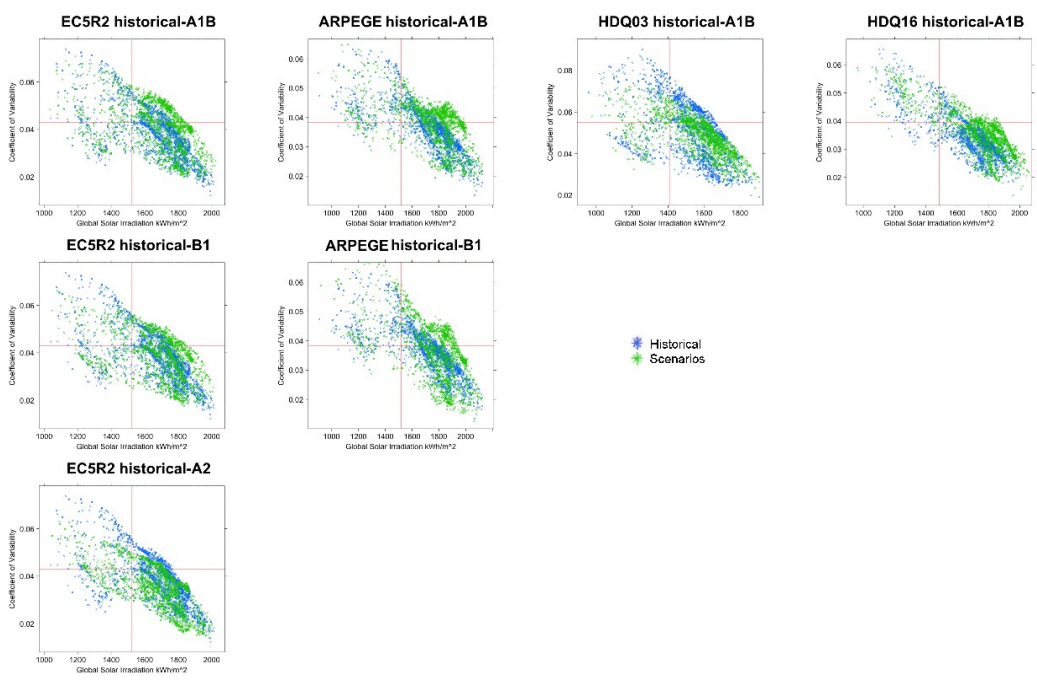

Figure8: Scatter-plot of global solar radiation against coefficient of variability for the different scenarios. The dividing red lines correspond to the irradiation and variability values at half the range of all the observed values over the IP (see CMSAF plot in Fig. 4). Blue points correspond to the historical (present climate) runs, while green points correspond to future scenario runs.
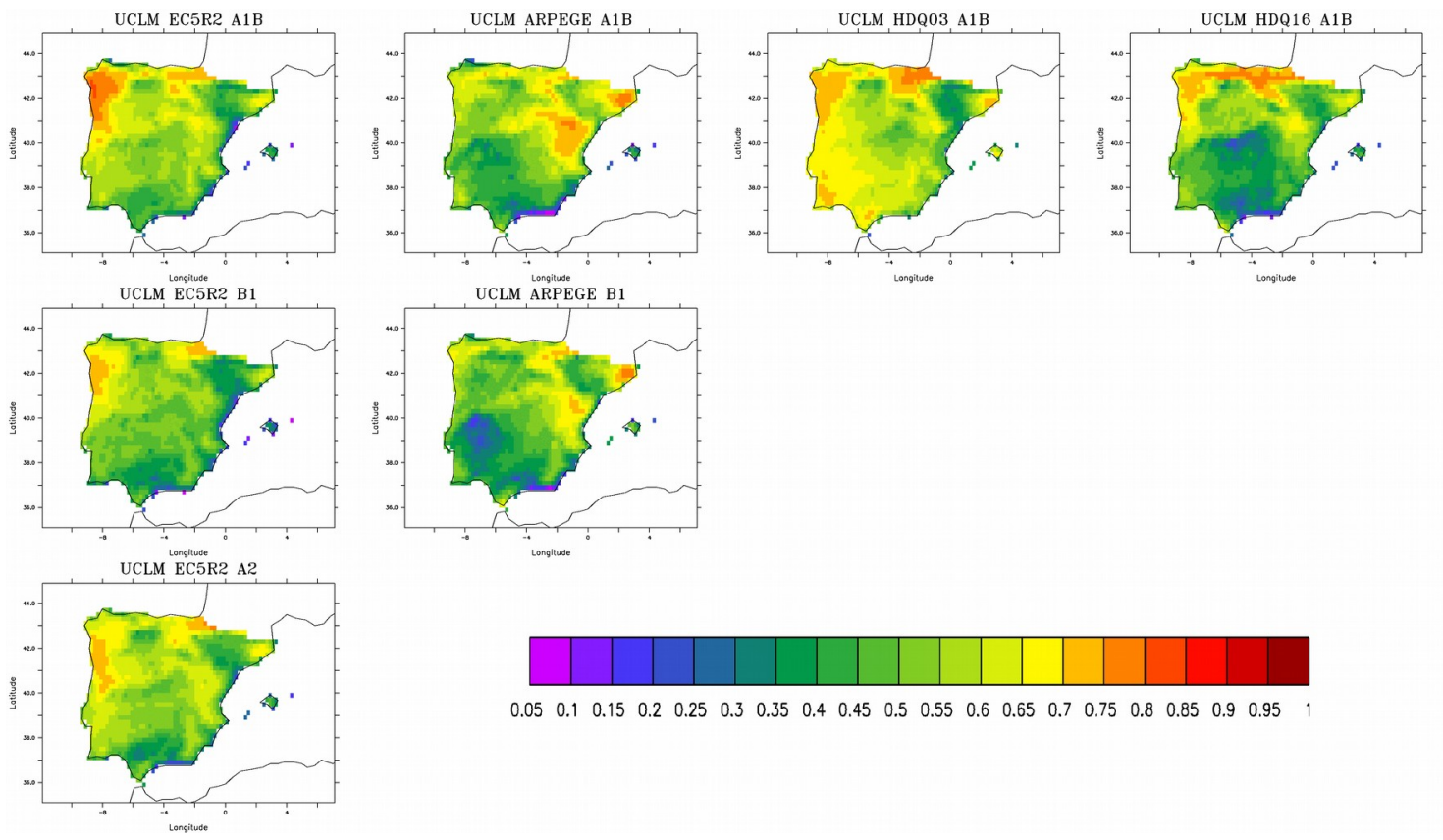

Figure 9: Values of temporal correlation between anomaly of temperature and rsds for summer (JJA). 


\section{APPENDIX A}

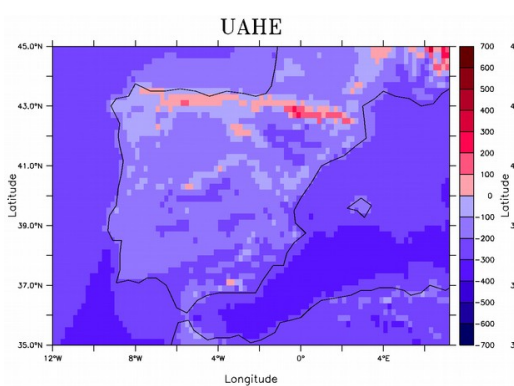

UCLM

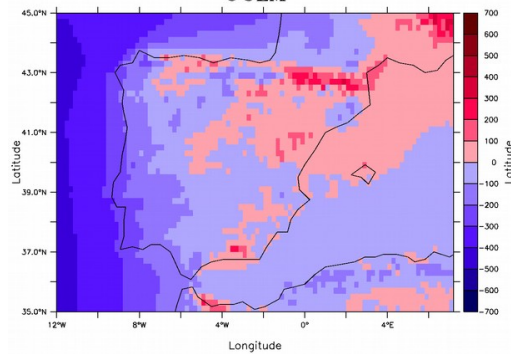

UCANA

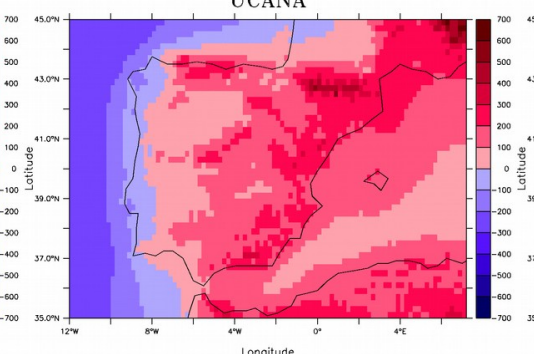

Longitude
UMU
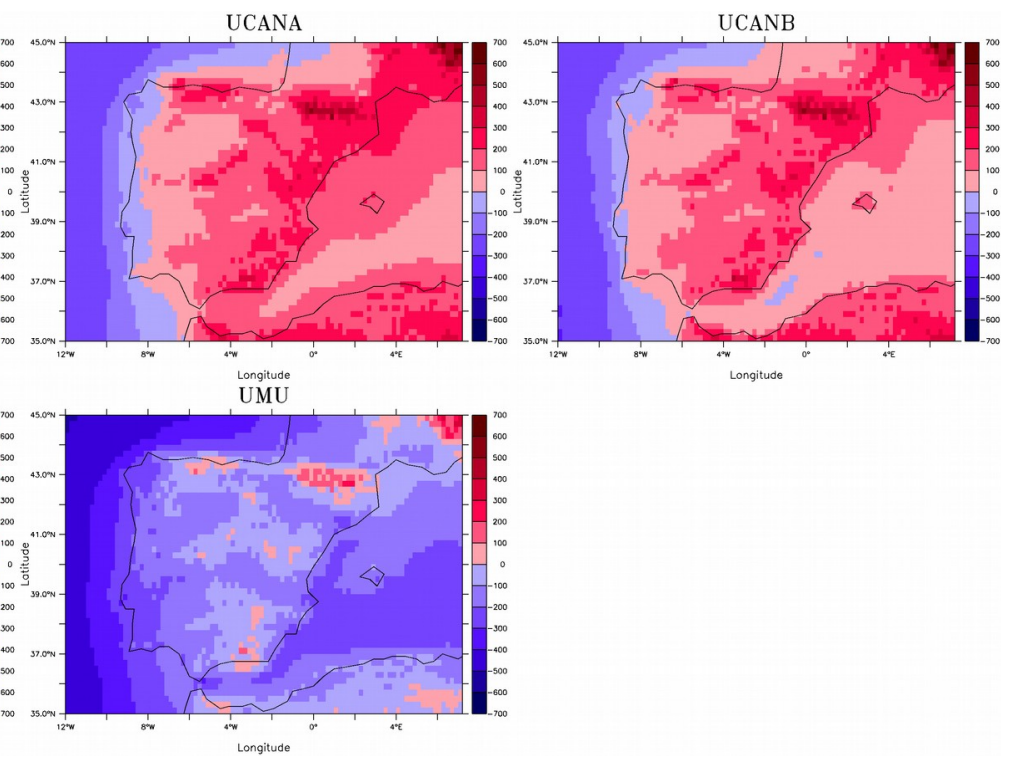

Figure A.1: Values of annual bias of accumulated surface downwelling shortwave radiation $\left(\mathrm{kWhm}^{-2}\right)$ for the $5 \mathrm{RCMs}$. 

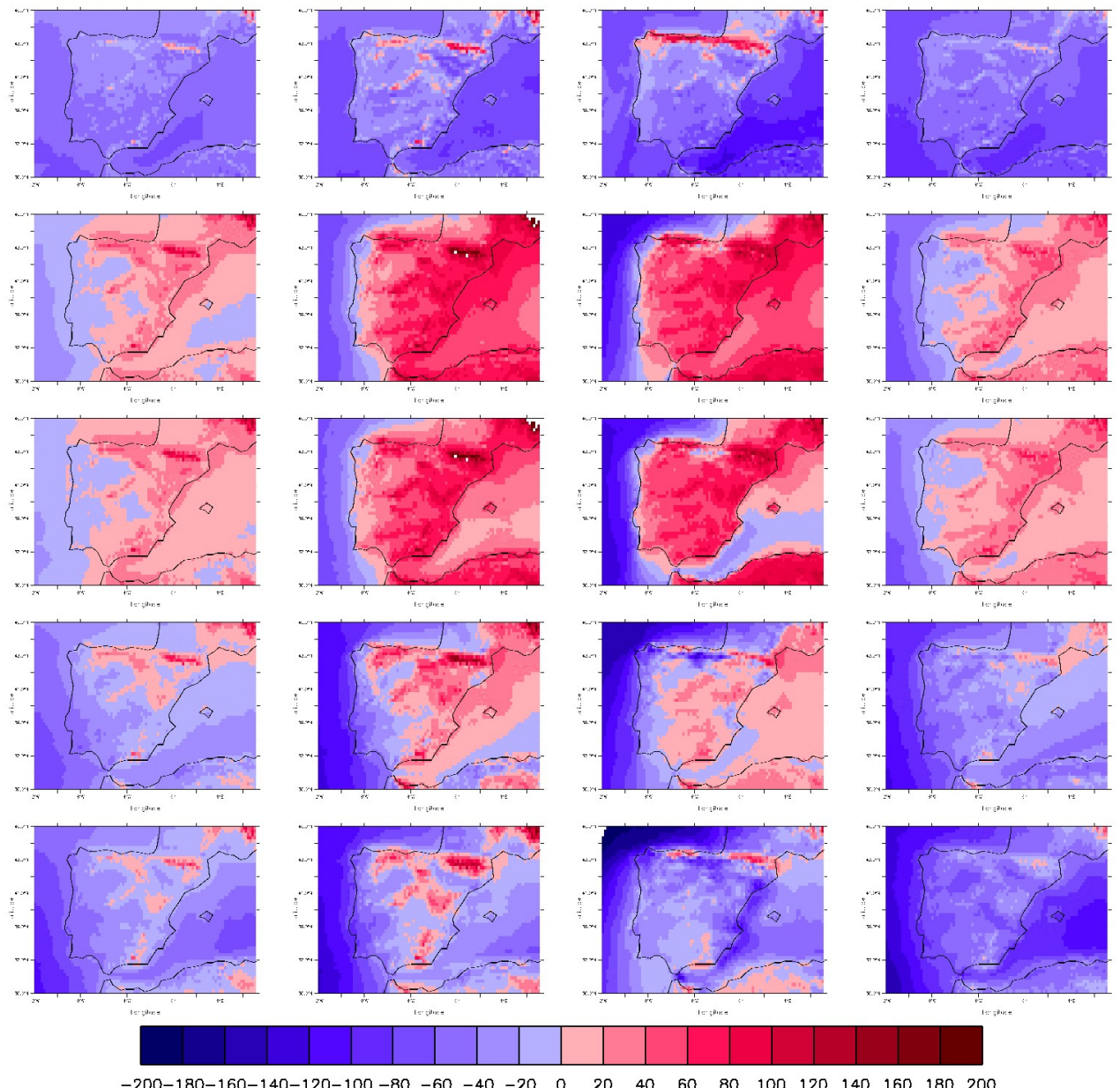

Figure A.2: Values of seasonal bias of accumulated surface downwelling shortwave radiation

$\left(\mathrm{kWhm}^{-2}\right)$. Each column represents one season (left to right) winter, spring, summer and autumn. The rows correspond to the models (top to bottom) UAHE, UCAN-A, UCAN-B, UCLM and UMU. 

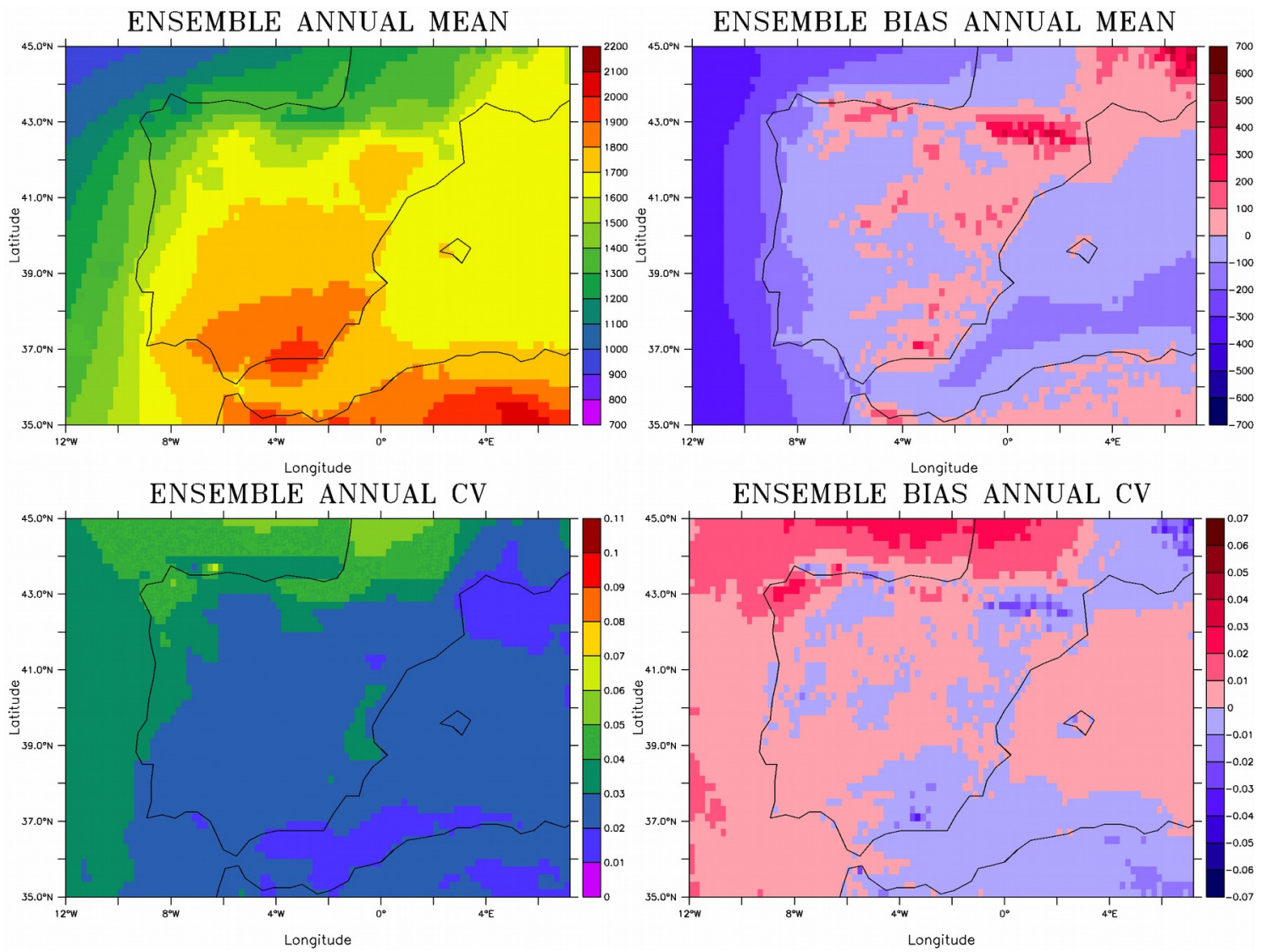

ENSEMBLE BIAS ANNUAL CV

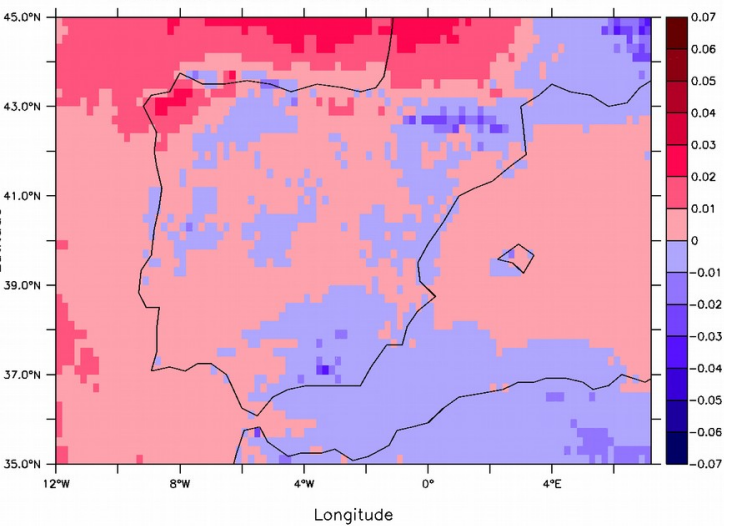

Figure A.3: Values of annual mean of accumulated surface downwelling shortwave radiation $\left(\mathrm{kWhm}^{-2}\right)$ and bias (top) and values of annual CV of accumulated radiation and bias (bottom) for the ensemble mean.
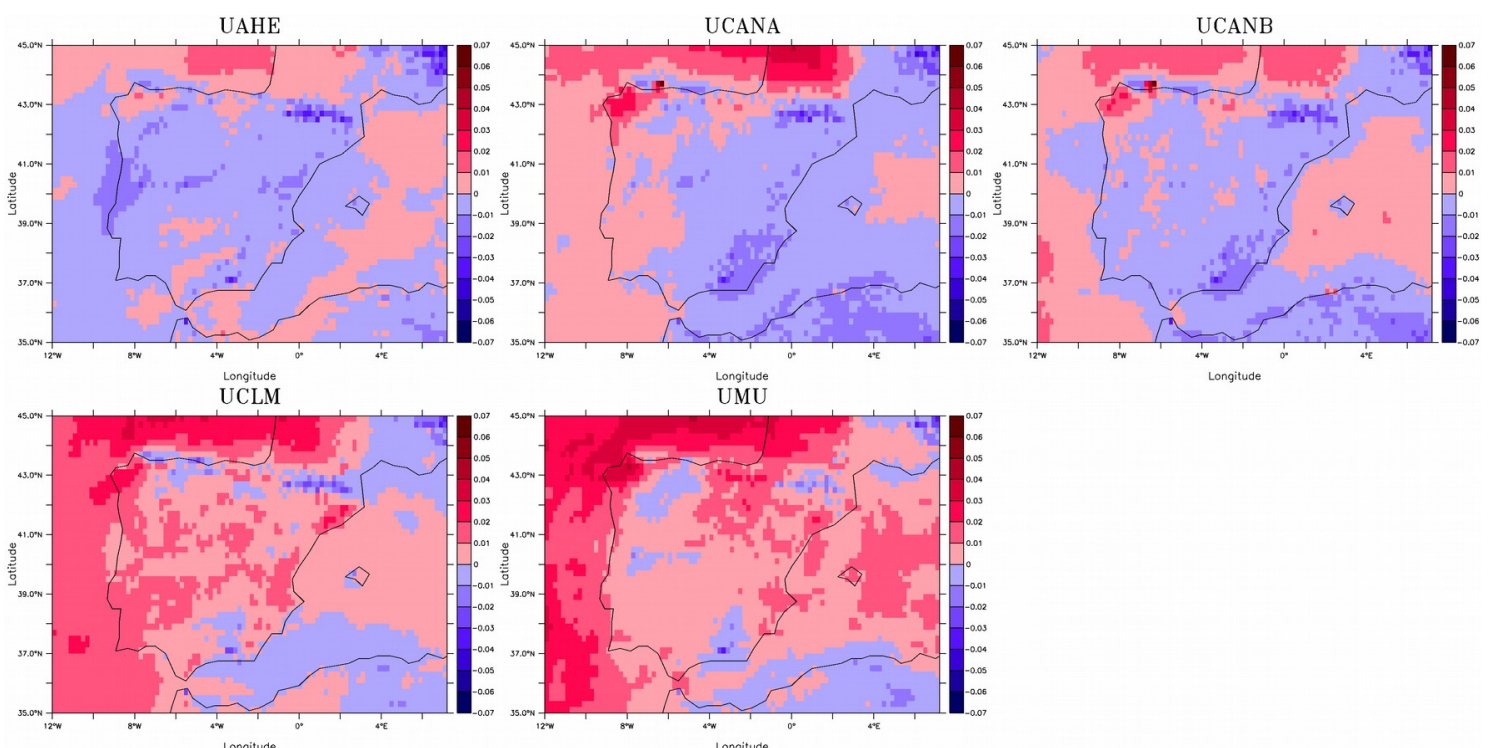

Figure A.4: Values of annual bias of $\mathrm{CV}$ of accumulated radiation for the $5 \mathrm{RCMs}$. 

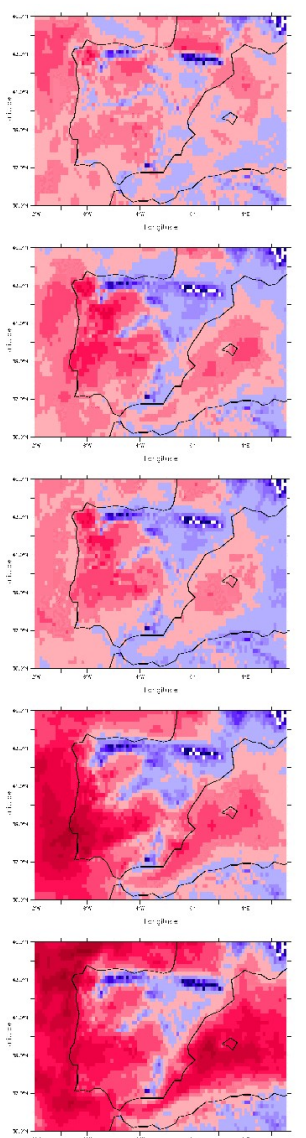
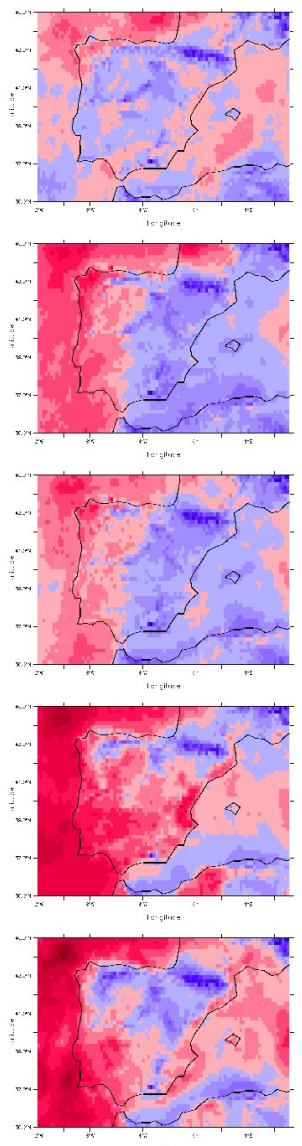
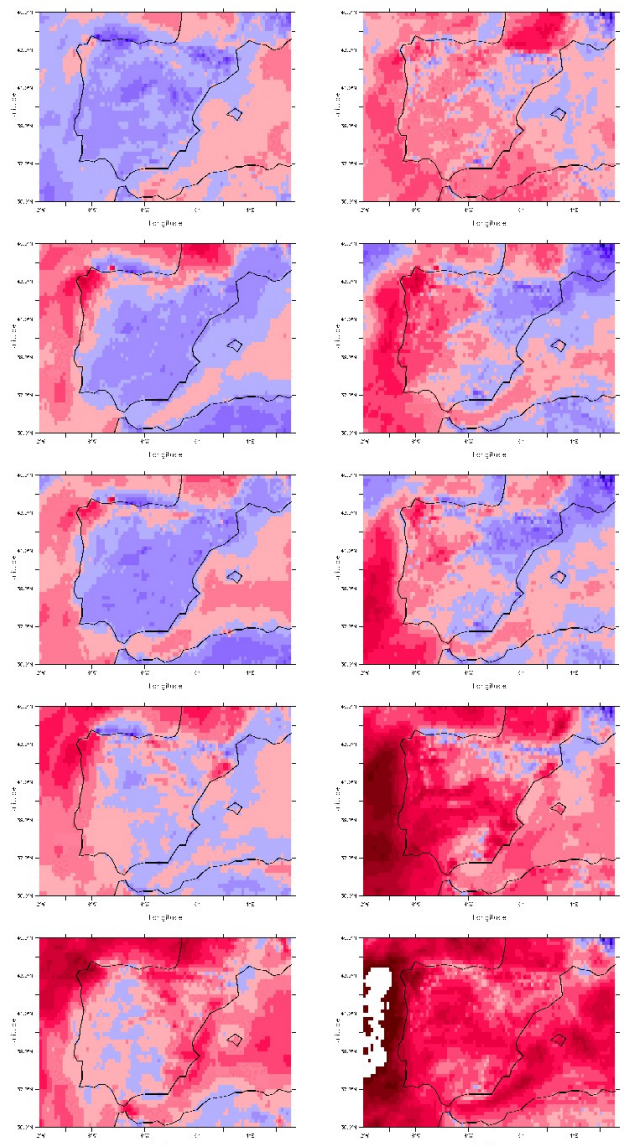

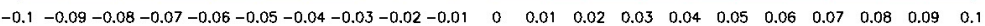

Figure A.5: Values of seasonal bias of CV of accumulated radiation. Each column represents one season (left to right) winter, spring, summer and autumn. The rows correspond to the models (top to bottom) UAHE, UCAN-A, UCAN-B, UCLM and UMU. 